\title{
PRE-MARITAL SCREENING TESTS OF $\beta$-THALASSEMIA TRAIT IN DAKSHINA KANNADA POPULATION OF KARNATAKA
}

\author{
SURESH BABU T. V. ${ }^{1}$, SARITHA ${ }^{2}$, ASHWINI S. ${ }^{3}$, MANJULA SHANTARAM ${ }^{4,5}$ \\ 1,2,3,4Department of Studies in Biochemistry, Mangalore University, PG Centre, Chikka Aluvara, Kodagu, Karnataka, India, 571232, \\ ${ }^{5}$ Department of Biochemistry, Yenepoya Medical College, Yenepoya University, Mangalore, India, 575018 \\ Email: manjula59@gmail.com
}

Received: 24 Nov 2016 Revised and Accepted: 21 Dec 2016

\section{ABSTRACT}

Objective: $\beta$-Thalassemia is one of the familiar single gene disorders which passes from parents to offspring. The prevalence of $\beta$-thalassemia trait varies from 1-14\% in different regions of India. Every year almost $9000 \beta$-thalassemic major children are being born in the Indian sub-continent. In the present study, the prevalence of $\beta$-thalassemia trait was checked and some screening tests were performed to detect it among the Dakshina Kannada population of Karnataka.

Methods: A total of 800 youngsters were selected for the study, males being above $21 \mathrm{y}$ and females above $18 \mathrm{y}$. Two ml of blood was drawn and collected in K2 EDTA bottles and complete hemogram was immediately checked. Samples which have Mean Corpuscular Volume (MCV) $<80$ fico litres(fl) were selected for the study. Five discriminant functions were calculated. NESTROFT (Naked Eye Single Tube Red Cell Osmotic Fragility Test) was performed in all the samples. The samples which show positive for NESTROFT and at least 2 discriminant functions were further checked for $\mathrm{HbA} 2$ level using cellulose acetate electrophoresis to confirm the $\beta$-thalassemia trait. A comparison was made with the normal samples which have MCV > 80fl.

Results: Prevalence of $\beta$-thalassemia trait was found to be $5.125 \%$ in this population. The obtained values were analyzed using unpaired Student's't test using GraphPad prism (Version-3.0). Samples of $\beta$-thalassemia trait have significant changes in the white blood corpuscles (WBC $p=0.1266$ ), red blood corpuscles (RBC $\mathrm{p}=0.0130)$, hemoglobin ( $\mathrm{Hb} \mathrm{p}<0.0001)$, hematocrit (HCT $\mathrm{p}<0.0001), \mathrm{MCV}(\mathrm{p}<0.0001)$, mean corpuscular hemoglobin (MCH $\mathrm{p}<0.0001$ ), mean corpuscular hemoglobin concentration (MCHC $\mathrm{p}<0.0001)$, platelets (PLT $\mathrm{p}=0.0005), \mathrm{HbA2}(\mathrm{p}<0.0001)$ compared to normal controls.

Conclusion: The present study shows that the people with $\beta$-thalassemia trait have a significant variation in complete hemogram compared to normal; NESTROFT and discriminant functions can be used for the screening of $\beta$-thalassemia trait in the population.

Keywords: $\beta$-Thalassemia trait, Complete hemogram, Discriminant functions, NESTROFT, Cellulose acetate electrophoresis

(c) 2017 The Authors. Published by Innovare Academic Sciences Pvt Ltd. This is an open access article under the CC BY license (http://creativecommons.org/licenses/by/4. 0/) DOI: http://dx.doi.org/10.22159/ijpps.2017v9i2.16320

\section{INTRODUCTION}

$\beta$-Thalassemia is one of the familiar single gene disorders which pass from parents to offspring, which is caused due to impaired production of $\beta$ hemoglobin chains [1]. As per the information $\beta$ thalassemia is one of the common genetic disorders in the world [2]. Various studies have found that the prevalence of $\beta$-thalassemia trait varies from $4-15 \%$ in different regions of India. Every year almost $9000 \beta$-thalassemic major children are being born in the Indian subcontinent and the carrier frequency of $\beta$-thalassemia varies from 3 to $20 \%$ [3]. Prevalence is found to be more in northern, western and eastern parts of India. Compared to all the states of India, Gujarat has the highest frequency of $\beta$-thalassemia trait $(10.0$ to $15.0 \%)$ which is followed by Calcutta (10.2\%), Punjab (6.5\%), Delhi (5.5\%), Tamil Nadu (4.0\%), Bengal (3.5\%), Mumbai (2.6\%), Maharashtra (1.9\%) and Kerala (0.6\%) [4]. India which is known for various cultural backgrounds with different ethnicities has an elevated inherited disorder rate in certain communities. In population screening it has been revealed that some of the communities have a risk of $\beta$-thalassemia and the carrier status prevalence is as high as $17 \%$ [5]. Based on the population distribution [6-13], a higher frequency of $\beta$-thalassemia is found in the people of Bhanishali (15.0\%), Lohana (13.6\%), Sindh (8.0\%), Assam (5.0\%), Saraswelt North West (4.4\%), Saraswelt West (3.5\%), Bangalen $(3.7 \%)$ and Ahom (1.0\%), Panjabis and Jains (4-7\%). $\beta$ Thalassemia has been classified into three types-minor, intermedia and major. $\beta$-Thalassemia minor is also called as $\beta$-thalassemia trait(BTT) or carrier state and the affected person carries one normal and one mutated thalassemia $\beta$ globin chain. There are $25 \%$ chances of developing a homozygous $\beta$-thalassemic major child for a $\beta$-thalassemia carrier couple [14]. Thalassemia is cost effective. To get an ideal treatment for one thalassemic child it costs around Rs.1,25,000/annum [15]. There is a lack of awareness about this disease among the people. There are many different screening techniques available to screen $\beta$-thalassemia.

In the present study, an attempt was made to screen $\beta$-thalassemic trait among the youngsters in Dakshina Kannada district, in Karnataka and to bring awareness among them. Dakshina Kannada is one of the coastal districts in Karnataka which have western ghats $[16,17]$. Dakshina Kannada is considered as the number one in literacy in Karnataka [18] but many of them do not know about $\beta$ thalassemia. In the prosperous families too, $\beta$-thalassemic children are being born

Hence, well-educated youngsters were selected to screen for $\beta$ thalassemia prevalence in Dakshina Kannada and also enumerated various tests available to screen.

\section{MATERIALS AND METHODS}

\section{Sample collection}

A total of 800 youngsters were selected for the study. Informed consent was obtained from all the subjects. Ethical clearance was obtained from Yenepoya University Ethics Committee YUEC $38 / 05 / 02 / 2015$

Inclusion Criteria: Unmarried people, males being above $21 \mathrm{y}$ and females above $18 \mathrm{y}$.

Exclusion Criteria: People who underwent recent blood transfusion. Informed consent was obtained from all the people. 


\section{Methodology}

Two ml of blood was collected in K2 EDTA bottle and complete hemogram was investigated immediately using Sysmex XP-100.
Samples which have $\mathrm{MCV}<80$ fico litres were selected for the study. NESTROFT (Naked Eye Single Tube Red Cell Osmotic Fragility Test) was performed in all the samples using $0.36 \%$ buffered saline [19].

Five discriminant functions (DF) were calculated using the formula and cut off points [20].

\begin{tabular}{llll}
\hline 1. & DF1 $=$ MCV-RBC- $(5 \times H b)-3.4$. & BTT $<0$ & (England and Fraser) $[21]$ \\
2. & DF2 $=$ MCVRBC. & BTT $<13$ & (Mentzer ratio) \\
3. & DF3 $=$ MCH $/$ RBC & BTT $<3.8$ & (Srivastava ratio) \\
4. & DF4 $=\left(\right.$ MCV ${ }^{2} \times$ MCH 0.01 & BTT $<1530$ & (Shine and Lal product) \\
5. & DF5 $=$ RBC Counts & BTT $>5 \times 10[12] / 1$ & (Klee) \\
\hline
\end{tabular}

The samples which show positive for NESTROFT and positive for at least 2 discriminant functions were further checked for HbA2 level using cellulose acetate haemoglobin electrophoresis [22] to confirm the $\beta$-thalassemia trait. If $\mathrm{HbA} 2>3.5 \%$, then it is considered as positive for $\beta$ thalassemia trait. Cellulose acetate strips and control ( $\mathrm{HbA}$ and $\mathrm{HbA2}$ ) were purchased from HELENA laboratory.

\section{Statistical analysis}

The obtained values were analyzed using unpaired Student's' $t$ ' test using GraphPad prism (Version-3.0) to find out the significant mean values of lab parameters. SPSS version 16 was used to find out the sensitivity, specificity, positive predictive value and negative predictive value. Microsoft excel was used to generate the graphs.

\section{RESULTS AND DISCUSSION}

Totally 800 samples were collected for this study and a complete hemogram was immediately checked. MCV<80fl was further screened for the $\beta$-thalassemia trait using NESTROFT. Totally $15 \%$ of the population have $\mathrm{MCV}<80 \mathrm{fl}$ (fig. 1).

NESTROFT is the simple low cost test which is used for population screening for $\beta$-thalassemia trait. Out of 120 samples, 72 samples were positive for NESTROFT. In the positive samples, the turbidity was observed and the line behind the test tube was not visible (fig. 3). In the negative samples, since there is no turbidity, the line was visible (fig. 2).

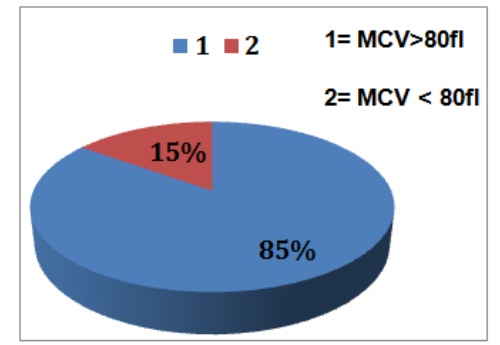

Fig. 1: Prevalence of $\mathrm{MCV}<\mathbf{8 0 f l}$

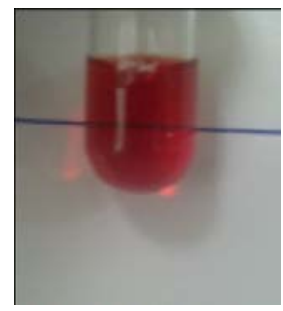

Fig. 2: Sample negative for NESTROFT

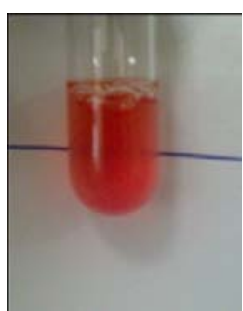

Fig. 3: Sample positive for NESTROFT
Samples which show positive for NESTROFT and for at least 2 discriminant functions were further checked for $\mathrm{HbA2}$ level using cellulose acetate haemoglobin electrophoresis to confirm $\beta$-thalassemia trait. $\mathrm{HbA} 2>3.5 \%$ is considered as $\beta$-thalassemia trait (fig. 4).

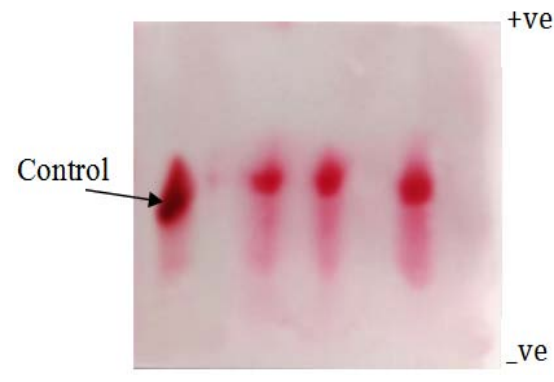

Fig. 4: Cellulose acetate electrophoresis

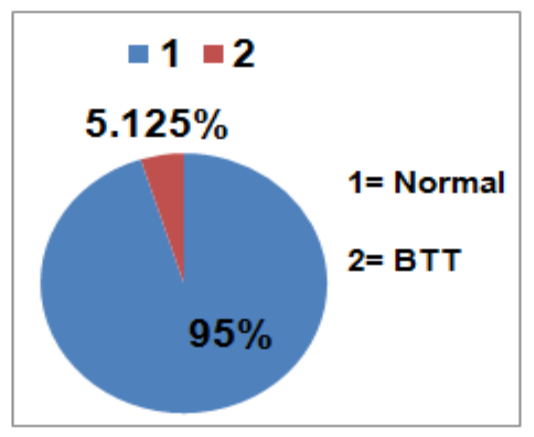

Fig. 5: Prevalence of $\beta$-thalassemia trait

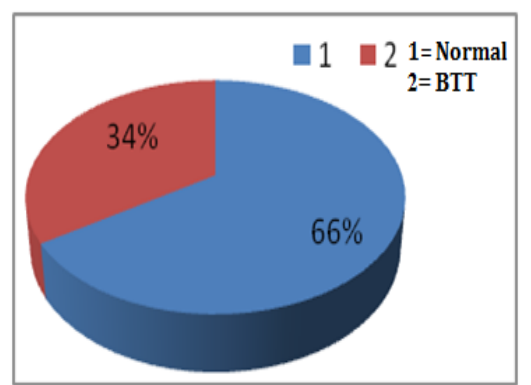

Fig. 6: Prevalence of $\beta$-thalassemia trait in $\mathrm{MCV}<80 \mathrm{fl}$

The prevalence of $\beta$-thalassemia trait was found to be $5.125 \%$ in this population (fig. 5). Thirty-four percent of the population is affected with $\beta$-thalassemia trait whose MCV value is less than $80 \mathrm{fl}$ (fig. 6). 
Table 1: Comparison of complete hemogram between $\beta$-thalassemia trait and healthy control blood samples

\begin{tabular}{|c|c|c|c|c|}
\hline S. No. & Parameters (mean \pm SD) & $\beta$-thalassemia trait $(n=41)$ & Healthy controls $(n=41)$ & p value \\
\hline 1. & $\mathrm{WBC}\left(\mathrm{x} 10^{3} / \mu \mathrm{l}\right)$ & $7.883 \pm 0.2918$ & $8.605 \pm 0.3655$ & 0.1266 \\
\hline 2. & $\mathrm{RBC}\left(\mathrm{x} 10^{6} / \mu \mathrm{l}\right)$ & $5.081 \pm 0.1067$ & $4.767 \pm 0.06265$ & 0.0130 \\
\hline 3. & $\mathrm{Hb}(\mathrm{g} / \mathrm{dL})$ & $10.67 \pm 0.3238$ & $13.34 \pm 0.2319$ & $\mathrm{p}<0.0001$ \\
\hline 4. & HCT $(\%)$ & $35.97 \pm 0.7252$ & $41.05 \pm 0.5727$ & $\mathrm{p}<0.0001$ \\
\hline 5. & $\operatorname{MCV}(\mathrm{fl})$ & $70.70 \pm 0.8396$ & $85.85 \pm 0.5937$ & $\mathrm{p}<0.0001$ \\
\hline 6. & MCH (pg) & $20.91 \pm 0.4188$ & $27.88 \pm 0.3061$ & $\mathrm{p}<0.0001$ \\
\hline 7. & $\operatorname{MCHC}(\mathrm{g} / \mathrm{dL})$ & $29.51 \pm 0.3354$ & $32.44 \pm 0.1976$ & $\mathrm{p}<0.0001$ \\
\hline 8. & Platelet $\left(\mathrm{x} 10^{3} / \mu \mathrm{l}\right)$ & $379.1 \pm 14.22$ & $315.1 \pm 10.59$ & 0.0005 \\
\hline
\end{tabular}

$\mathrm{HCT}=$ Hematocrit; MCV= Mean corpuscular volume; $\mathrm{MCH}=$ Mean corpuscular hemoglobin; MCHC= Mean corpuscular hemoglobin concentration.

Complete hemogram of the blood samples was compared between $\beta$-thalassemia trait (BTT) and healthy controls (table1). WBC value was slightly high in control $(8.605 \pm 0.3655)$ when compared to BTT (7.883 \pm 0.2918$)$; RBC level was high in BTT $(5.081 \pm 0.1067)$ compared to controls $(4.767 \pm 0.06265)$; Hb, HCT, MCV, MCHC were significantly low in BTT when compared to the controls and the platelets were significantly high in BTT $(379.1 \pm 14.22)$ compared to the controls (315.1 \pm 10.59$)$.

Table 2: Comparison of discriminant functions between $\beta$-thalassemia trait and healthy control blood samples

\begin{tabular}{llll}
\hline Parameters (mean \pm SD) & $\boldsymbol{\beta}$-thalassemia trait $(\mathbf{n = 4 1 )}$ & Healthy controls $(\mathbf{n = 4 1 )}$ \\
\hline DF1 & $8.907 \pm 1.579$ & $11.04 \pm 1.121$ & $\mathbf{p}$ value \\
DF2 & $14.20 \pm 0.3845$ & $18.08 \pm 0.2908$ & 0.2746 \\
DF3 & $4.801 \pm 0.5224$ & $5.854 \pm 0.09788$ & $\mathrm{p}<0.0001$ \\
DF4 & $1061 \pm 42.92$ & $2069 \pm 52.05$ & 0.0512 \\
DF5 & $5.081 \pm 0.1067$ & $4.767 \pm 0.06265$ & 0.0001 \\
\hline
\end{tabular}

DF2 and DF4 were significantly low in BTT when compared to controls while DF1 and DF3 were slightly lower in BTT than the healthy controls. DF5 is slightly elevated in BTT when compared to controls (table 2).

Table 3: HbA2 levels in BTT and control

\begin{tabular}{llll}
\hline Parameter (mean \pm SD) & $\boldsymbol{\beta}$-thalassemia trait $(\mathbf{n}=\mathbf{4 1})$ & Healthy controls $(\mathbf{n}=\mathbf{4 1})$ & $\mathbf{p}$ value \\
\hline $\mathrm{HbA} 2 \mathrm{~g} / \mathrm{dL}$ & $4.951 \pm 0.1280$ & $2.591 \pm 0.0799$ & $\mathrm{p}<0.0001$ \\
\hline
\end{tabular}

The HbA2 level above $3.5 \%$ up to $6.5 \%$ was considered as $\beta$ thalassemia trait and below $3.5 \%$ is considered as normal. When we screened the HbA2 using cellulose acetate haemoglobin electrophoresis, it was found that the mean value of HbA2 in BTT affected samples was significantly high when compared to controls (table 3).

Table 4: Association of complete hemogram with $\beta$-thalassemia trait samples whose $\mathrm{MCV}<80 \mathrm{fl}$

\begin{tabular}{|c|c|c|c|}
\hline Parameters & BTT $(n=41)$ & Non BT (Non $\beta$-thalassemia) $(n=79)$ & Total $(n=120)$ \\
\hline WBC $\left(>11000 \times 10^{3} / \mu \mathrm{l}\right)$ & $4(9.75 \%)$ & $5(6.32 \%)$ & $9(7.5 \%)$ \\
\hline $\mathrm{RBC}\left(>5 \times 10^{6} / \mu \mathrm{l}\right)$ & $20(48.78 \%)$ & $27(34.17 \%)$ & $47(39.16 \%)$ \\
\hline $\mathrm{Hb}(<10 \mathrm{~g} / \mathrm{dL})$ & $14(34.14 \%)$ & $18(22.7 \%)$ & $32(26.66 \%)$ \\
\hline HCT $(<35 \%)$ & $17(41.46 \%)$ & $25(31.64 \%)$ & $42(35 \%)$ \\
\hline $\mathrm{MCH}(<26.5 \mathrm{pg})$ & $40(97.56 \%)$ & $77(97.46)$ & $117(97.5 \%)$ \\
\hline $\mathrm{MCHC}(<31.8 \mathrm{~g} / \mathrm{dL})$ & $37(90.24 \%)$ & $70(88.60 \%)$ & $107(89.16 \%)$ \\
\hline
\end{tabular}

BTT and non $\beta$ thalassemia cases whose $\mathrm{MCV}<80 \mathrm{fl}$ were checked for risk factors of complete hemogram. In BTT, 4 (out of 41) and Non BT 5 (out of 79) totally 9 samples (out of 120 ) have shown WBC $>11000$ $\mathrm{x} 10^{3} / \mu \mathrm{l} ; 20$ samples of BTT and 27 samples of Non BT and a total of 47 have $\mathrm{RBC}>5 \times 10 \% / \mu \mathrm{l} ; \mathrm{Hb}<10 \mathrm{~g} / \mathrm{dL}$ was found in 14 samples in BTT and 18 samples in non BT, totally 32 samples; in HCT<35\%, seventeen samples have shown positive in BTT cases and 25 samples showed positive in Non BT cases, thus entirely 42 cases showed positive; 40 BTT and 77 non BT and overall 117 samples had $\mathrm{MCH}<26.5 \mathrm{pg} ; \mathrm{MCHC}<31.8 \mathrm{~g} / \mathrm{dL}$ was initiated in $37 \mathrm{BTT}$ and 70 Non BTT and a total of 107 samples (table 4). Discriminant functions in the population which have $\mathrm{MCV}<80 \mathrm{fl}$ was checked. Eight BTT and 17 Non BT, totally 25 subjects showed positive for DF1; positive for DF2 was present in 13 BTT and 24 Non BT subjects, totally 37; DF3 $<3.8$ was seen in 11 cases in BTT and 5 cases in Non BT, a sum of 16 cases; 40 samples of BTT and 72 samples of Non BT, entirely 112 samples have DF4<1530; 37 samples of BTT and 70 samples of Non BT, a sum of 107 have DF5 > $5 \times 10^{6} / \mu \mathrm{l}$ (table 5 ).

Table 5: Association of discriminant functions with $\beta$-thalassemia trait in samples whose $\mathrm{MCV}<80 \mathrm{fl}$

\begin{tabular}{lll}
\hline Parameters & $\boldsymbol{\beta}$-thalassemia trait (n=41) & Non $\boldsymbol{\beta}$-thalassemia (n=79) \\
\hline DF1 $(<0)$ & $8(19.5 \%)$ & $17(21.51 \%)$ \\
DF2 $(<13)$ & $13(31.70 \%)$ & $24(30.37 \%)$ \\
DF3 $(<3.8)$ & $11(26.82 \%)$ & $5(6.32 \%)$ \\
DF4 $(<1530)$ & $40(97.56 \%)$ & $72(91.39 \%)$ \\
DF5 $\left(>5 \times 10^{6} / \mu \mathrm{l}\right)$ & $37(90.24 \%)$ & $70(88.60 \%)$ \\
\hline
\end{tabular}


Among discriminant functions highest sensitivity was found in DF2, DF3, DF4 which showed 100\% sensitivity followed by DF1 which showed $92.5 \%$ and DF5 with $65 \%$ sensitivity. DF5 have highest specificity of $100 \%$ followed by DF4 97.6\%, DF1, DF2, DF3 have least specificity. False positive rate was found high in DF1 80.5\%,
DF3 73.2\%, DF2 68.3\%, DF4 had less and in DF5 false positive rate was absent. DF4 showed highest false negative rate followed by DF1 $7.3 \%$ and in DF2, DF3, DF4 false negative rate was absent. NESTROFT showed $94.5 \%$ sensitivity, $97.1 \%$ specificity, $2.9 \%$ false positive rate, $5.4 \%$ false negative value (table 6 ).

Table 6: Diagnostic values of discriminant functions

\begin{tabular}{|c|c|c|c|c|}
\hline Discriminant functions & Sensitivity & Specificity & False positive rate & False negative rate \\
\hline DF1 & $92.5 \%$ & $19.5 \%$ & $80.5 \%$ & $7.3 \%$ \\
\hline DF2 & $100 \%$ & $31.7 \%$ & $68.3 \%$ & $0 \%$ \\
\hline DF3 & $100 \%$ & $26.8 \%$ & $73.2 \%$ & $0 \%$ \\
\hline DF4 & $100 \%$ & $97.6 \%$ & $2.4 \%$ & $0 \%$ \\
\hline DF5 & $65 \%$ & $100 \%$ & $0 \%$ & $34.9 \%$ \\
\hline NESTROFT & $94.6 \%$ & $97.1 \%$ & $2.9 \%$ & $5.4 \%$ \\
\hline
\end{tabular}

Complete hemogram was compared with other studies, in which $\mathrm{RBC}$ value of our study was almost the same as other studies. Hb,
MCHC values were little less and MCV, MCH values were slightly high in the present study when compared to other studies (table 7).

Table 7: Comparison of laboratory parameters among various studies in BTT

\begin{tabular}{|c|c|c|c|c|c|c|}
\hline Study & Number of cases(n) & $\operatorname{RBC}\left(>5 \times 10^{6} / \mu \mathrm{l}\right)$ & $\mathrm{Hb}(<10 \mathrm{~g} / \mathrm{dL})$ & $\operatorname{MCV}(f l)$ & MCH (pg) & MCHC (g/dL) \\
\hline Gupta et al., [23] & $\mathrm{n}=56$ & $5.6 \pm 0.7$ & $11.2 \pm 1.4$ & $64.5 \pm 3.7$ & $20 \pm 1.2$ & $31.2 \pm 0.94$ \\
\hline Mohamed et al., [24] & $n=382$ & $5.45 \pm 0.71$ & $11.3 \pm 1.45$ & $64.81 \pm 4.72$ & $20.75 \pm 1.64$ & - \\
\hline Khin et al., [25] & $n=133$ & $5.9 \pm 1.0$ & $11.5 \pm 1.6$ & $62.7 \pm 12.1$ & $19.9 \pm 3.5$ & $29.3 \pm 2.2$ \\
\hline Madan et al., [26] & $\mathrm{n}=337$ & $5.56 \pm 0.76$ & $11.6 \pm 1.6$ & $64.7 \pm 4.8$ & $20.6 \pm 3.6$ & - \\
\hline Sujatha et al., [20] & $\mathrm{n}=34$ & $5.76 \pm 1.16$ & $11.01 \pm 2.06$ & $60.56 \pm 5.58$ & $18.78 \pm 3.45$ & $30.52 \pm 2.56$ \\
\hline Present Study & $n=41$ & $5.081 \pm 0.10$ & $10.67 \pm 0.32$ & $70.70 \pm 0.83$ & $20.91 \pm 0.41$ & $29.51 \pm 0.33$ \\
\hline Present Study Control & $n=41$ & $4.767 \pm 0.06$ & $13.34 \pm 0.23$ & $85.85 \pm 0.59$ & $27.88 \pm 0.30$ & $32.44 \pm 0.19$ \\
\hline
\end{tabular}

NESTROFT has been compared with the other studies. All the studies show greater sensitivity (above 90\%) whereas 64.2\% and 66.6\% specificity was exhibited by the studies of Mangalni et al., and Susanna et al., respectively. In our study, we found $97.1 \%$ specificity (table 8).

Table 8: Comparison of NESTROFT among various studies in BTT

\begin{tabular}{|c|c|c|c|}
\hline Study & Number of cases(n) & Sensitivity & Specificity \\
\hline Maheshwari et al. [27] & $\mathrm{n}=1048$ & $91 \%$ & $95 \%$ \\
\hline Mangalni et al. [28] & $n=1695$ & $94.4 \%$ & $64.2 \%$ \\
\hline Mehta et al. [29] & $n=131$ & $99.2 \%$ & $75.8 \%$ \\
\hline Susanna et al. [30] & $n=137$ & $98.7 \%$ & $66.6 \%$ \\
\hline Raghavan et al. [31] & - & $95.5 \%$ & $87.0 \%$ \\
\hline Sujatha et al. [20] & $n=222$ & $90 \%$ & $97.34 \%$ \\
\hline Present study & $n=41$ & $94.6 \%$ & $97.1 \%$ \\
\hline
\end{tabular}

\section{CONCLUSION}

Eight hundred unmarried youngsters were selected for the study and their complete hemogram was checked immediately in which $\mathrm{MCV}<80 \mathrm{fl}$ were selected and NESTROFT was done. Discriminant functions were calculated. The samples which showed positive for NESTROFT and the samples which showed positive for at least two discriminant functions were further checked for HbA2 using cellulose acetate haemoglobin electrophoresis to confirm $\beta$ thalassemia trait. Fifteen percent of the population have $\mathrm{MCV}<80 \mathrm{fl}$. The pre-marital prevalence of $\beta$-thalassemia trait in Dakshina Kannada district was found to be $5.125 \%$. NESTROFT showed $94.6 \%$ sensitivity, $97.1 \%$ specificity, $2.9 \%$ false positive rate, $5.4 \%$ false negative rate and DF4 which showed 100\% sensitivity, $97.6 \%$ specificity, $2.4 \%$ false positive rate, $0 \%$ false negative rate. These are the best methods for population screening of $\beta$-thalassemia trait. NESTROFT, RBC $>5 \times 10^{6} / \mu$ l and lower values of $\mathrm{Hb}$ also seem to be the best combination to screen $\beta$-thalassemia trait. Mean HbA2 in $\beta$ thalassemia trait was found to be $4.95 \mathrm{~g} / \mathrm{dL}$.

\section{ACKNOWLEDGEMENT}

Authors would like to thank Mangalore University and Yenepoya Research Centre, Yenepoya University for their support and encouragement.

\section{CONFLICT OF INTERESTS}

Declared none

\section{REFERENCES}

1. Nasser AA, Al-Hamdan, Yagob YA, Fahad MA, Abdul JC Premarital screening for thalassemia and sickle cell disease in Saudi Arabia. Genet Med 2007;9:372-7.

2. El-Hazmi AF, Warsy AS. Hemoglobinopathies in Arab countries. Oxford University Press 1999;30:83-110.

3. Weatherall DJ. The diagnostic features of the different forms of thalassaemia. Haematology 1983;1:1-26.

4. Pirastu M, Ristaldi MS, Loudianos G, Murru S, Sciarratta GV, Parodi MK, et al. Molecular analysis of atypical betathalassemia heterozygotes. Ann NY Acad Sci 1990;612:90-7.

5. Verma IC. Burden of genetic disorders in India. Indian J Paediatr 2000;67:893-8.

6. Vaz FE, Thakur CB, Banerjee MK, Gangal SG. Distribution of beta-thalassemia mutations in the Indian population referred to a diagnostic centre. Haemoglobin 2000;24:181-94.

7. Kiss TL, Ali MA, Levine M, Lafferty JD. An algorithm to aid in the investigation of thalassemia trait in multicultural populations. Arch Pathol Lab Med 2000;124:1320-3. 
8. Shanthi G, Balasubramanyam D, Srinivasan R. Clinical and demographical studies of beta $(\beta)$-thalassemia in Tamilnadu. Res J Pharm Chem Biol Sci 2013;4:952-61.

9. Mehta BC, Dave VB, Joshi SR, Baxi AJ, Bhatia HM, Patel JC. Study of hematological and genetic characteristics of Kutchi Bhanushali Community. Indian J Med Res 1972;60:305-11.

10. Sukumaran PK. Abnormal haemoglobins in India. Sree Saraswati Press 1975;1:225-61.

11. Chouhan DM, Chouhan V. Epidemiology: symposium on thalassemia. Indian J Hematol Blood Transf 1992;10:1-6.

12. Jawahirani A, Mamtani M, Das K, Rughwani V, Kulkarni H. Prevalence of beta thalassemia in sub-castes of Indian sindhis: results from a two-phase survey. Indian J Public Health 2007;121:193-8.

13. Mohanty D, Colah R, Gorakshakar A. Community control of thalassaemia syndromes-Awareness, screening, genetic counselling and prevention. A National Multicentric Task Force Study of Indian Council of Medical Research. New Delhi. ICMR; 2008.

14. Madan N, Sharma S, Sood SK, Colah R, Bhatia HM. The frequency of $\beta$-thalassemia and other hemoglobinopathies in northern and western India. Indian J Hum Genet 2010;16:16-25.

15. Rakholia $R$, Chaturvedi P. Prevalence of $\beta$ thalassemia carrier state in Sindhi community of Wardha and evaluation of risk factors for $\beta$ thalassemia trait. Nigerian J Clin Practice 2013;16:375-80.

16. Dakshina Kannada District: Census; 2011.

17. Ernst, Young. Dakshina Kannada-the afforest conurbation; 2012.

18. Daijiworld. Dakshina Kannada most literate district; 2016.

19. Gorakshaker C, Colah R, Nadkarni A, Desai S. Evaluation of the single tube osmotic fragility test in detection of B-thalassemia trait. Nat Med J India 1990;3:171-3.

20. Sujatha R, Sreekantha, Niveditha SR, Avinash SS, Remya, Vinodchandran, et al. The study of recent biochemical and pathological aspects of thalassemia. Int J Health Sci Res 2013;1:140-52.

21. England JM, Fraser PM. Differentiation of iron deficiency from thalassemia trait by routine blood count. Lancet 1973;1:449-52.

22. John O, Cornelis LH, Joanne TS, Mary P, Michael A, Renzo G. Prevention of thalassemias and other haemoglobin disorders: laboratory protocols. Thalassemia International Federation; 2012.

23. Gupta AD, Hegde C, Mistri R. Red cell distribution width as a measure of severity of iron deficiency in iron deficiency anemia. Indian J Med 1994;100:177-83.

24. Mohamed M, Edibany, Kameel F, Ninos JJ, Douglas R. Usefulness of certain RBC indices in diagnosing and differentiating thalassemia trait from Iron Deficiency anemia. Am J Clin Pathol 1999;111:676-82.

25. Khin EH, Aung MH, Thein M. Thalassemia in the outpatient department of the Yangon children's hospital in Myanmar: basic haematological values of thalassemia traits. South East Asian J Trop Med Public Health 1992;23:264-8.

26. Madan N, Meera S, Satendra S, Usha R, Kusum K. Red cells indices and discriminant functions in the detection of betathalassemia trait in a population with high prevalence of iron deficiency Anemia. Indian J Pathol Microbiol 1999;42:55-61.

27. Maheshwari M, Arora S, Kabra M, Menon PSN. Carrier screening and prenatal diagnosis of beta-thalassemia. Indian Pediatr 1999;36:1119-25.

28. Manglani M, Lokeshwar MR, Vani VG, Nishi B, Vijay M, 'NESTROFT'-An effective screening test for beta-thalassemia trait. Indian Pediatr 1997;34:702-7.

29. Mehta BC, Gandhi S, Mehta S. Screening for beta thalassemia trait with naked eye single tube red cell osmotic fragility test in hematology clinics. Indian J Hematol Blood Transf 1991;9:133-6.

30. Susanna T, Srivastana A, Jayaseelan L, Dennison D, Chandy C NESTROFT as a screening test for the detection of thalassemia and common haemoglobinopathies-An evaluation against a high-performance liquid chromatographic method. Indian J Med Res 1996;104:194-7.

31. Raghavan K, Lokeshwar MR, Birewar N, Nigam V, Mangalani MV, Raju. Evaluation of naked eye single tube red cell osmotic fragility test in detecting $\beta$-thalassemia trait. Indian Pediatr 1991;28:469-72.

\section{How to cite this article}

- $\quad$ Suresh Babu TV, Saritha, Ashwini S, Manjula Shantaram. Premarital screening tests of $\beta$-thalassemia trait in Dakshina kannada population of Karnataka. Int J Pharm Pharm Sci 2017;9(2):268-272 